\title{
Good and Bad Sleep in Childhood: A Questionnaire Survey amongst School Children in Southern Italy
}

\author{
Gianluca Ficca, ${ }^{1}$ Francesca Conte, ${ }^{1}$ Vittoria De Padova, ${ }^{1}$ and Iole Zilli ${ }^{2}$ \\ ${ }^{1}$ Department of Psychology, University of Naples II, Via Vivaldi 43, 81100 Caserta, Italy \\ ${ }^{2}$ Department of Psychology, University of Florence, Via di San Salvi 12, Padiglione 26, 50135 Firenze, Italy
}

Correspondence should be addressed to Gianluca Ficca, gianluca.ficca@unina2.it

Received 15 July 2011; Accepted 13 November 2011

Academic Editor: Halszka Oginska

Copyright ( 2011 Gianluca Ficca et al. This is an open access article distributed under the Creative Commons Attribution License, which permits unrestricted use, distribution, and reproduction in any medium, provided the original work is properly cited.

Despite its clinical importance, the issue of subjective sleep quality in children remains unexplored. Here we investigate, in school-aged children, the prevalence of bad sleep perception and its relationships with sleep habits and daytime functioning, to provide hints on its possible determinants. Subjective sleep perception, sleep habits, and daytime functioning were studied through a questionnaire survey in a sample of 482 children (6-12 yrs.). Being "bad sleeper" was reported by $6.9 \%$ of the sample. Compared to the "good sleepers", these subjects displayed shorter sleep duration on schooldays, longer sleep latencies, and a more pronounced evening preference, beyond more frequent insufficient sleep. Though no differences emerged in sleepiness, bad sleepers showed higher impairments in daytime functioning, indicated by more frequent depressed mood and impulsivity. These distinctive features might be very important to precociously detect those children who are possibly more vulnerable to sleep disturbances and whose sleep-wake rhythms evolution should be paid particular attention thereafter.

"The good people sleep much better at night than the bad people. Of course, the bad people enjoy the waking hours much more" Woody Allen

\section{Introduction}

Good sleep is extremely important for all aspects of health and wellbeing in humans.

But what exactly does "good sleep" mean? A first basic distinction should be made between those characteristics that can be considered "objective" indicators of sleep quality and the subjective perception of sleeping well.

The latter is extremely important in itself since subjective sleep complaints, which are the most frequent reason for seeking medical help, are not necessarily concordant with what objectively measured, as highlighted by a number of studies, conducted both in normal $[1,2]$ and pathological populations [3-5], and in different age groups $[6,7]$.

In children, the first question that still requires a definite answer is how many of them believe their sleep is good. In fact, data on the prevalence of good sleep perception are scarce over the whole life span.
Most of the available data concerns the adult population: in 2005, the USA National Sleep Foundation [8] reported that $26 \%$ of the adult population claim that they have "a good night's sleep" only a few nights a month or less. Previous European surveys have reported the presence of sleep dissatisfaction in $10.1 \%$ of the Italian population [9], 11.9\% of the Finnish [10], 10.1\% of the Portuguese [11], and 7\% of the German [12].

In their classical paper on subjective sleep quality in aging, Buysse and colleagues [13] found that almost $70 \%$ of people aged more than 80 fell within a categorically defined range for "good" sleepers.

As for younger populations, data on subjective sleep quality perception are even scarcer. Despite a number of surveys in children and adolescents reporting a high prevalence of sleep problems, such as night awakenings [14], nightmares [14], nocturnal enuresis [15], and sleep-onset delay [16], the question of the global subjective perception of sleep 
quality in childhood has been almost totally neglected. Indeed, only one study on 449 toddlers has directly assessed sleep satisfaction in this population, by means of a question on their global sleep quality perception [17]. Mediocre or bad quality of sleep was reported by $22.4 \%$ of the sample. However, in this research, subjective perception was only taken into account as one of the factors, the others being objective sleep features, contributing to a global "quality of sleep" score.

Both in the clinical and the experimental fields [18], optimal sleep duration, sleep continuity, and sleep organization are considered main indicators of objective sleep quality [19]. These features do not necessarily correspond to those required for subjective judgments of good sleep.

Actually, subjective determinants of sleep quality perception have been only occasionally studied in the adult individual. Among sleep features it seems that sleep continuity [20] and the ease of sleep onset [21] play a pivotal role, but perceived depth of sleep [22] and sleep duration [23] have been proposed as relevant determinants as well. Concerning waking features, ease of waking [24], freshness on waking $[25,26]$ and throughout the day $[24,25]$ are the factors appearing to give the greater contribution.

However, there is very little systematic knowledge on factors underlying sleep satisfaction judgments both in children and in the elderly and on whether these determinants might exhibit age-related differences. Indeed, only one recent work by Zilli and coworkers [7] was carried on elderly subjectswho were shown to evaluate their own sleep quality as mainly dependent on sleep latency and length rather than on continuity and thus to maintain a perception of good sleep despite the high number of awakenings — and not even one study on this topic has so far regarded childhood.

Finally, daytime functioning in children has been investigated in relation to objective measures of sleep or self-reported sleep habits and problems: in these studies, a number of sleep features such as degree of fragmentation [27], sleep duration [28], difficulties of falling asleep [29], and sleepiness [30] have been shown to relate to children daytime functioning and school performance. However, again, due to the lack of data on subjective sleep quality, it remains to be ascertained whether and to what extent sleep satisfaction in children could be related to the quality of their waking.

Thus, aims of this study are

(1) to determine the prevalence of sleep satisfaction in a sample of children in Southern Italy;

(2) to investigate how dissatisfied children differentiate from satisfied ones as far as sleep habits, subjective evaluation of sleep characteristics, circadian preference, vigilance levels, and daytime functioning are concerned.

\section{Materials and Methods}

2.1. Subjects. The survey has been carried out from May to June 2009 in three public Elementary Schools, respectively located in S. Nicola La Strada (Caserta), Naples, and Pomigliano d'Arco (Naples). These schools were randomly
TABLE 1: Demographic characteristics of the sample.

\begin{tabular}{lccccc}
\hline & $N$ & $M$ & $F$ & $6-8$ years & 9-12 years \\
\hline Total sample & 482 & $240^{*}$ & $240^{*}$ & 164 & 318 \\
S. Nicola La Strada & 117 & 52 & 65 & 26 & 91 \\
Naples & 83 & 40 & 43 & 31 & 52 \\
Pomigliano d'Arco & 282 & 148 & 132 & 107 & 175 \\
\hline
\end{tabular}

* Summing up the number of subjects in the males and females groups does not yield the total sample number since two children did not report their sex on the questionnaire.

selected from the list of all Elementary Schools in Campania, a wide region of southern Italy.

Headmasters of the selected schools were first contacted through a formal letter, introducing the research and the professionals involved. For those who positively answered, all the procedures, instruments, and aims of the study were explained in a further meeting, extended to teachers and parents' representatives. A final meeting served to illustrate the study to all children's parents and to collect their informed consent.

Four hundred eighty-two students were recruited for the study, the only exclusion criterion being the presence of a diagnosed cognitive or learning disorder.

Table 1 displays the demographic characteristics of the sample.

2.2. Instrument. The instrument used in the study is the School Sleep Habits Survey [31-34] in its Italian version [3537]. The questionnaire includes the following:

(1) questions assessing sleep habits on both schooldays and weekends: three of these are open questions, addressing sleep duration and bedtime and rise time in hours and minutes; two others, investigating the reasons for going to bed and rising at a given time, are multiple choice questions with seven predetermined answers;

(2) one question on habitual sleep latency, consisting of a single forced-choice item with six response categories ("0 to 5 minutes", " 6 to 15 minutes", " 16 to 30 minutes", " 31 to 45 minutes", "46 to 60 minutes", "more than one hour");

(3) a context and vigilance scale, composed of nine items assessing the ease of staying awake in different situations ("talking vis a vis with someone else", "travelling on public transports", "watching a show", "watching television or listening to music", "reading or studying", "during a school test", "sitting in class", "working at the computer", "playing a videogame"). Respondents had to choose among four ordinal alternatives, ranging from "no difficulty staying awake" to "struggling to stay awake but falling asleep". A global vigilance score was then obtained by summing up scores at all of the nine items;

(4) a sleep-wake behavioural problems scale, made up of 17 items which assesses, over the last two weeks, how often the subjects have experienced some sleep $\backslash$ wakerelated perceptions and problems, ("being happy about one's sleep", "being late at school for having 
slept too long", "falling asleep in class", "waking up too early without being able to go back to sleep", "going to bed late in the evening", "staying awake all night long", "sleeping until noon", "feeling tired or sleepy during the day", "having difficulties waking up in the morning", "having problems falling asleep at bedtime", "having nightmares", "going to bed too early because of excessive sleepiness", "doing something dangerous", "sleeping well", "feeling sad or depressed", "feeling anxious or nervous", "feeling very worried"). The answers are graded on a five-point scale, ranging from "never" to "always";

(5) a morningness-eveningness questionnaire (MEQ), composed of ten items assessing circadian preference to discriminate subjects in morning types (M-types), intermediate types (I-types), and evening types (Etypes).

(6) Finally, an item about sleep quality perception ("Do you consider yourself as a good or a bad sleeper?") was added to the original Italian version of the questionnaire [35], as well as a forced question examining whether sleep duration is considered sufficient: ("How often do you think you sleep enough?", with five choices: "always", "often", "sometimes", "seldom", "never").

2.3. Procedure. Questionnaires were administered by an experimenter, in presence of the teachers, during school hours. In view of the subjects' young age, the experimenter remained in the classroom throughout the administration procedure, being available to answer any question arising during the questionnaire completion. He was specifically instructed to provide standardized answers, which included question rephrasing and examples.

2.4. Data Analysis. After descriptive statistics, the global sample was split in two groups ("good sleepers" and "bad sleepers"), based on the answer to the question assessing overall subjective sleep quality. The prevalence of good and bad sleepers was calculated for the total sample, for males and females separately, and, to detect age-related differences, within two different age groups: 6-8 and 9-12 years.

Good and bad sleepers were then compared for the following dependent variables:

(a) sleep habits, that is, sleep duration in minutes, bedtime and rise time-all variables reported for schooldays and weekends-plus the differences between schooldays and weekends $(\Delta-\mathrm{SD} / \mathrm{WE})$ in bedtime, rise time, and sleep duration;

(b) sleep latency;

(c) sufficiency of sleep;

(d) circadian preference, calculated by summing up scores at the ten questions (lower scores being associated to a higher degree of eveningness);

(e) vigilance, calculated by summing up scores at the nine questions ranging from 1 to 4 , so to have a maximum score of 36 and a minimum score of 9 ;

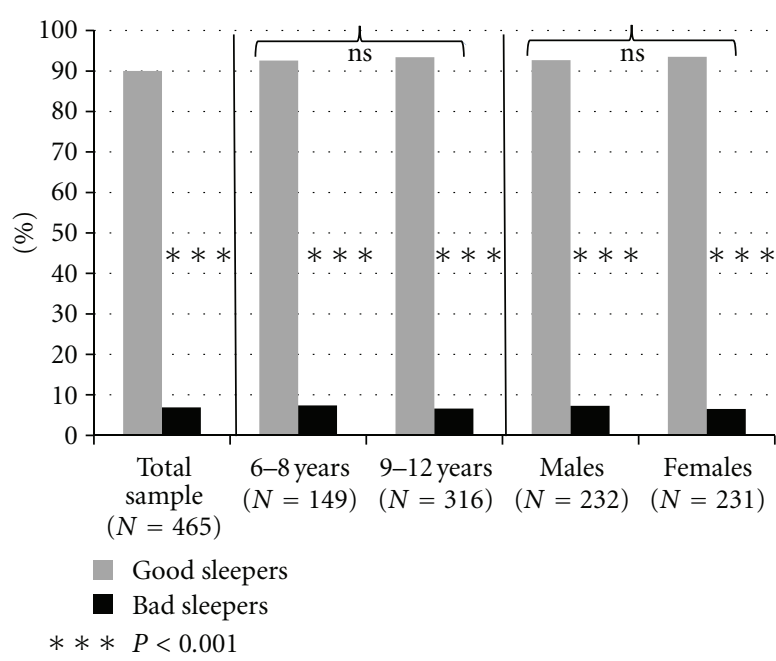

Figure 1: Prevalence of good and bad sleepers in the total sample, in two age groups (6-8 and 9-12 years), and across genders.

(f) sleep-wake behavioural problems, calculated by summing up scores at the seventeen questions ranging from 1 to 5 (higher scores corresponding to lower degrees of problems).

For comparisons, nonparametric Mann-Whitney $U$-test was used for all cardinal variables.

Chi-square test was carried for all binomial variables, as well as for analysis of frequency distribution of chronotypologies.

Furthermore, Pearson's analysis of correlation was carried between the overall sleep-wake behavioural problems score and sleep habits measures.

\section{Results}

3.1. Response Rate. The questionnaire was correctly filled by all children $(N=482)$. However, seventeen questionnaires had to be excluded for aberrant values. Thus, the final sample for data analysis included 465 children $(F=231, M=232$, two children did not report their sex; age range $6-12$ years, $6-8$ years: $N=149,9-12$ years: $N=316$ ).

3.2. Overall Sleep Quality. To the question about global sleep quality, $6.9 \%$ of the sample answered to be "bad sleepers", whereas 90\% answered to be "good sleepers", and 3.1\% did not answer (Figure 1). Bad sleepers percentages did not significantly change either across age (6-8 years: $7.4 \%, 9-12$ years: $6.6 \%$, chi $\left.^{2}=0.07, \mathrm{~ns}\right)$ or across genders $(M: 7.3 \%, F$ : $\left.6.5 \%, \mathrm{chi}^{2}=0.08, \mathrm{~ns}\right)$.

3.3. Sleep Habits and Sleep Features. Table 2 displays sleep onset time, rise time, and sleep duration in the general sample, as well as the results of the comparison for the same variables between good and bad sleepers. Sleep onset time is significantly delayed for bad sleepers both during schooldays $(P=0.025)$ and weekends $(P=0.027)$. Furthermore, sleep 
TABLE 2: Descriptive data on sleep habits and their comparison between good and bad sleepers.

\begin{tabular}{lcccc}
\hline Variables & $\begin{array}{c}\text { Total sample } \\
\text { Mean } \pm \text { SD }\end{array}$ & $\begin{array}{c}\text { Good sleepers } \\
\text { Mean } \pm \text { SD }\end{array}$ & $\begin{array}{c}\text { Bad sleepers } \\
\text { Mean } \pm \text { SD }\end{array}$ & Mann-Whitney test $(U)$ \\
\hline Sleep onset time on schooldays & $21: 46 \pm 01: 23$ & $21: 43 \pm 01: 22$ & $22: 22 \pm 01: 24$ & $\mathbf{5 3 0 8 , \mathbf { 0 } ^ { * }}$ \\
Sleep onset time on weekends & $22: 53 \pm 02: 08$ & $22: 50 \pm 01: 30$ & $23: 35 \pm 02: 10$ & $\mathbf{5 3 2 2 , \mathbf { 0 } ^ { * }}$ \\
Rise time on schooldays & $07: 20 \pm 00: 31$ & $07: 21 \pm 00: 32$ & $07: 18 \pm 00: 24$ & 6652,0 \\
Rise time on weekends & $09: 25 \pm 01: 31$ & $09: 23 \pm 01: 28$ & $09: 47 \pm 02: 01$ & 5838,50 \\
Sleep duration on schooldays & $09: 34 \pm 01: 24$ & $09: 37 \pm 01: 23$ & $08: 55 \pm 01: 25$ & $\mathbf{5 3 3 0 , \mathbf { 0 } ^ { * }}$ \\
Sleep duration on weekends & $10: 32 \pm 02: 30$ & $10: 33 \pm 02: 29$ & $10: 12 \pm 02: 37$ & $\mathbf{6 7 1 5 , 5}$ \\
\hline
\end{tabular}

${ }^{*} P<.05$.
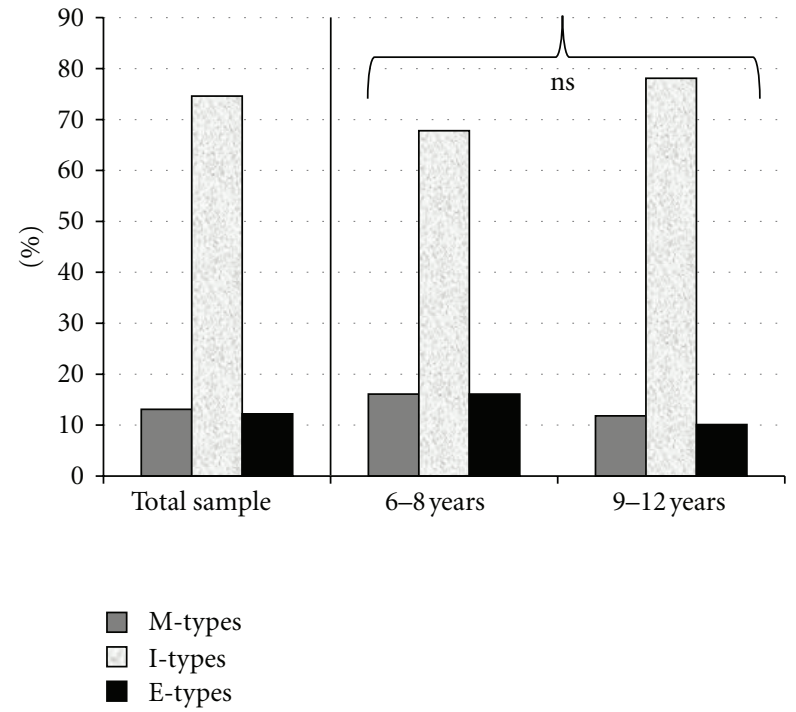

FIGURE 2: Frequency distribution of chronotypologies in the total sample and in two age groups (6-8 and 9-12 years).

duration is significantly shorter in bad sleepers compared to good sleepers in schooldays $(P=0.028)$. No significant differences were found in either rise time or sleep duration between bad and good sleepers during schooldays and weekends.

Also, the two groups did not significantly differ in the $\Delta$ SD/WE of bedtime $(U=6937.0, \mathrm{~ns})$, rise time $(U=5688.5$, $\mathrm{ns})$, and sleep duration $(U=5762.5, \mathrm{~ns})$.

3.4. Sleep Latency and Sufficiency of Sleep. Sleep latency is significantly longer in bad sleepers (good sleepers median $=2$, that is, "6 to 15 minutes"; bad sleepers median $=4$, that is, "31 to 45 minutes"; $U=4425.0, P<0.001)$. Moreover, bad sleepers report more frequent insufficient sleep (good sleepers median $=4$, that is, "seldom", bad sleepers median $=3$, that is, "sometimes"; $U=5403.0, P=0.034)$.

3.5. Circadian Preference. As shown in Figure 2, frequencies of M-types, I-types, and E-types were, respectively, 10.1\%, $74.6 \%$, and $12.2 \%$. No significant differences emerged in frequency distribution between the two age groups considered $\left(\right.$ chi $\left.^{2}=4.53, \mathrm{~ns}\right)$.
Significant differences were found in MEQ global scores between good and bad sleepers $(U=4088.5, P=0.003)$, with bad sleepers more frequently displaying an evening preference.

3.6. Context and Vigilance. No significant differences between bad and good sleepers were found either in the context and vigilance global score $(U=5844.5$, ns $)$ or in any of the items composing the scale.

3.7. Sleep-Wake Behavioural Problems. A significant difference emerged between bad and good sleepers at the sleepwake behavioural problems global score $(U=3575.5, P<$ 0.001 ), displayed in Table 3 together with the comparisons for all of the specific items showing a significant difference.

In addition, the global score in the overall sample showed significant correlations with rise time both in schooldays $(r=$ $-.095, P<0.001)$ and weekends $(r=-.122, P=0.02)$, whereas it was not significantly correlated with bedtime (schooldays: $r=-.095$, ns; weekends: $r=-.087$, ns), sleep duration (schooldays: $r=-.003$, ns; weekends: $r=-.003$ ), or $\Delta$-SD/WE measures (bedtime: $r=-.042$, ns; rise time: $r=$ -.056 , ns; sleep duration: $r=-.002$, ns).

\section{Discussion}

At best of our knowledge, this is the first study addressing subjective sleep quality perception in school-aged children and may contribute to trace the entire life-span trajectory of subjective sleep quality ratings and of their determinants.

In order to address habitual sleep in a relatively large sample, we decided to collect only subjective data by means of a standardized questionnaire with good reliability and validity properties [31-34], already confirmed in the Italian population [35-37]. However, at a further stage, these data might be complemented by objective sleep measures in smaller samples, over repeated consecutive nights.

As for our choice of directly asking for the perception of both sleep quality and sleep features to the children themselves, it was made at variance with the vast majority of the studies on children younger than 10 years, which have been based on parents' and teachers' reports. We are confident that this choice may be well rewarding. In terms of feasibility, our questionnaire was filled out by all children, without any specific difficulty in data collection. As for accuracy, we have 
TABLE 3: Comparison of sleep-wake behavioural problems between good and bad sleepers.

\begin{tabular}{|c|c|c|c|c|c|c|c|}
\hline \multirow[b]{2}{*}{ Variables } & \multicolumn{3}{|c|}{ Good sleepers } & \multicolumn{3}{|c|}{ Bad sleepers } & \multirow[b]{2}{*}{$U$ of Mann-Whitney Test } \\
\hline & Median & $1^{\circ}$ Quartil & $3^{\circ}$ Quartil & Median & $1^{\circ}$ Quartil & $3^{\circ}$ Quartil & \\
\hline Have been happy about your sleep & 4 & 4 & 4 & 3 & 1,5 & 3 & $4339,5^{* * *}$ \\
\hline Have had problems falling asleep & 4 & 3 & 4 & 2 & 1,75 & 2 & $4073^{* * *}$ \\
\hline Have had a nightmare & 4 & 2 & 4 & 2 & 2 & 2 & $5158^{* *}$ \\
\hline Have done something dangerous & 5 & 3 & 5 & 4 & 2 & 4 & $5216,5^{* *}$ \\
\hline Have slept well & 5 & 4 & 5 & 4 & 1,75 & 4 & $3242,5^{* * *}$ \\
\hline Have felt sad or depressed & 5 & 3 & 5 & 3 & 2 & 3 & $5012,5^{* *}$ \\
\hline $\begin{array}{l}\text { Sleep-wake behavioural problems } \\
\text { global score }\end{array}$ & 67 & 60 & 67 & 58 & 50,5 & 58 & $3575,5^{* * *}$ \\
\hline
\end{tabular}

${ }^{*} P<.05$.

${ }^{* *} P<.01$.

$* * * P<.001$

taken into account the severe limitation of parent-reports studies represented by the scarce concordance between adults' perceptions and children's objective sleep parameters $[38,39]$; in fact, parents appear to be accurate in reporting sleep schedule measures (sleep onset time, time in bed) but they tend to overestimate the duration and continuity of their children's sleep and therefore its global quality [39-41]. Also, parent-child agreement on the report of night-time awakenings was recently found to be remarkably low, and even lower was the concordance on overall subjective sleep quality [42]. Finally, Owens and coworkers [43] found that the differences in actigraphic sleep parameters between ADHD and control children were more often correlated with self-reports than with parent reports, thus emphasizing the importance of directly questioning the school-aged child.

In addition, though the reliability of self-reports in children at very early ages (6-8 years) could be questioned, this is not the first study concerning sleep habits that used selfreports in this age group $[40,44,45]$.

A first major result of the present survey is the rather low percentage $(6.9 \%)$ of school children claiming to be bad sleepers. We did not find any comparable data in the literature, since in the few studies on the same age group administering a question on subjective sleep quality, this question was part of a sleep log, thus referring to a specific night instead of assessing the subjective perception of habitual sleep [42-44].

Regarding sex, no difference in the percentage of bad sleepers was detected between males and females, at variance with data on adolescence, showing that subjectively assessed sleep quality indicators are better in girls than boys [46], and with studies on adult populations, reporting, conversely, higher percentages of sleep complaints in women [47], despite better objective sleep measures [48].

As for age differences, the prevalence of subjectively reported bad sleep in our group of children is lower than the one previously found both in adults [8-11] and old subjects [13], but almost identical to data from an Iranian study on high school students [49]. Together with the evidence that we did not find any significant difference of bad sleepers percentage when comparing two age subgroups within the whole sample, this might suggest that the prevalence of bad subjective sleep quality increases only after adolescence. A possible reason for this will be made clearer later on, after discussing our results on sleepiness levels and daytime behavioural problems.

In our sample, bad sleepers' sleep duration was lower than that of good sleepers on schooldays. Also, they reported insufficient sleep more often than good sleepers and longer sleep latencies, as well as delayed sleep onset time on both schooldays and weekends.

Furthermore, the bad sleepers group displayed a higher global score on the sleep-wake behavioural problems scale. In particular, it is noteworthy that bad sleepers reported significantly higher scores at the items "have done something dangerous" and "have felt sad and depressed", suggesting a somehow more impulsive attitude and a tendency to depressed mood.

Both the previously mentioned data about sleep features and the presence of a poorer daytime functioning compared to good sleepers might be explained by looking at chronotypologies through the morningness-eveningness questionnaire results. In general terms, we have detected an equal frequency of evening and morning types in the total sample-slightly above $10 \%$, similar to the one of the adult population-and no differences between our two age groups, which range from elementary schoolchildren (6-8 years) to prepubertal children (9-12 years). This suggests that the high frequency of eveningness, often observed in adolescence $[35,46]$, is peculiar of that specific age and not preceded by a gradual shift towards it.

However, what is most interesting for our purposes is our data concerning a clear evening preference for bad sleepers. This result is consistent with Giannotti and coworkers' finding [37] of a high prevalence of self-reported poor sleep in evening-type (E-type) adolescents (about one third of the E-type group), and with the higher presence of sleep-wake behavioural problems in E-types relative to other chronotypes $[35,37]$. Indeed, as also noted by Russo and colleagues [35], the higher prevalence of sleep-related problems in Etypes could be explained as a result of "social jet-lag", a concept introduced by Wittmann and colleagues [50] to indicate 
the misalignment between individual biological rhythms and the social rhythm imposed by school schedule.

On the other hand, no difference emerged between bad and good sleepers' scores on the context and vigilance scale. Though in contrast with the negative influence of sleep disturbances on daytime sleepiness, described in most of the literature (see e.g., [51, 52]), the possibility that the reported sleep problems do not impact daytime vigilance levels receives support from a previous study on an adult population [53], in which E-types, who presented repeated episodes of sleep restriction and irregular sleep-wake schedules, did not rate themselves as sleepier than morning and normal chronotypes.

Moreover, in a very recent meta-analysis on children's sleep and cognition, after publication bias correction-a necessary step in the meta-analytic process-total sleep time and sleep efficiency displayed no correlation with daytime sleepiness, whereas the relationship between sleep and behaviour was indeed significant (Rebecca Astill, personal communication).

In light of these results, we can trace two hypotheses on the determinants of poor sleep perception in our bad sleepers group. On one hand, it is possible to consider their sleep quality judgments as the result of objectively worse sleep features, which would on their turn influence mood and impulsive attitudes though not impacting perceived alertness. If this is the case, sleep duration and latency are possibly the main determinants, as confirmed by the finding that bad sleepers report perception of insufficient sleep and difficulties falling asleep more frequently than good sleepers, similarly to what observed in the elderly [7].

Yet, these differences might be negligible although significant, and bad sleep perception could be the consequence of additional factors other than sleep itself. In the first place, as proposed by some authors $[25,54]$, sleep satisfaction judgments could be partly or fully determined by cognitive biases. In other words, the presence during waketime of specific emotional and behavioural problems, such as depressed mood and impulsivity, may lead to retrospectively define sleep quality as poor and unsatisfactory. Moreover, as mentioned above, an important role may be played by "social jet lag", although no difference in "social jet-lag measures" between good and bad sleepers was found in our sample.

This alternative view might also provide an answer to the aforementioned question on the increase in the prevalence of poor sleep perception occurring from adolescence onward. The main factor interfering with judgments on sleep quality would actually be perceived wake quality, which is often dramatically worsened at that age as a result of many factors, including modified life styles and more challenging social and work demands.

On the basis of our evidence, it would be hazardous to privilege or discard any of these two major hypotheses, which are likely to be not mutually exclusive and to interact in determining children's poor sleep judgments, as it was shown to happen in insomniac adults as well $[25,54]$.

In conclusion, the subjective perception of sleep characteristics and daytime behavioural features seems quite peculiar in the group of children reporting themselves as bad sleepers. This observation is of great clinical interest, in that it strongly suggests a possibility to set specific strategies aimed to screen and precociously detect those subjects who might be more vulnerable than others to sleep disturbances over the life span.

\section{References}

[1] D. S. Lauderdale, K. L. Knutson, L. L. Yan, K. Liu, and P. J. Rathouz, "Sleep duration: how well do self-reports reflect objective measures? The CARDIA sleep study," Epidemiology, vol. 19, pp. 838-845, 2008.

[2] S. W. Lockley, D. J. Skene, and J. Arendt, "Comparison between subjective and actigraphic measurement of sleep and sleep rhythms," Journal of Sleep Research, vol. 8, no. 3, pp. 175183, 1999.

[3] J. Fernandez-Mendoza, S. L. Calhoun, E. O. Bixler et al., "Sleep misperception and chronic insomnia in the general population: role of objective sleep duration and psychological profiles," Psychosomatic Medicine, vol. 73, no. 1, pp. 88-97, 2011.

[4] J. Choi, I. Y. Yoon, H. W. Kim, S. Chung, and H. J. Yoo, "Differences between objective and subjective sleep measures in children with attention deficit hyperactivity disorder," Journal of Clinical Sleep Medicine, vol. 6, no. 6, pp. 589-595, 2010.

[5] A. Okifuji and B. D. Hare, "Nightly analyses of subjective and objective (actigraphy) measures of sleep in fibromyalgia syndrome: what accounts for the discrepancy?" Clinical Journal of Pain, vol. 27, no. 4, pp. 289-296, 2011.

[6] J. F. van den Berg, H. M. E. Miedema, J. H. M. Tulen, A. Hofman, A. K. Neven, and H. Tiemeier, "Sex differences in subjective and actigraphic sleep measures: a population-based study of elderly persons," Sleep, vol. 32, no. 10, pp. 1367-1375, 2009.

[7] I. Zilli, G. Ficca, and P. Salzarulo, "Factors involved in sleep satisfaction in the elderly," Sleep Medicine, vol. 10, no. 2, pp. 233-239, 2009.

[8] National Sleep Foundation, "Adult sleep habits and styles," Sleep in America Poll, 2005, http://www.sleepfoundation.org.

[9] M. M. Ohayon and S. Smirne, "Prevalence and consequences of insomnia disorders in the general population of Italy," Sleep Medicine, vol. 3, no. 2, pp. 115-120, 2002.

[10] M. M. Ohayon and M. Partinen, "Insomnia and global sleep dissatisfaction in Finland," Journal of Sleep Research, vol. 11, no. 4, pp. 339-346, 2002.

[11] M. M. Ohayon and T. Paiva, "Global sleep dissatisfaction for the assessment of insomnia severity in the general population of Portugal," Sleep Medicine, vol. 6, no. 5, pp. 435-441, 2005.

[12] M. M. Ohayon and J. Zulley, "Correlates of global sleep dissatisfaction in the German population," Sleep, vol. 24, no. 7, pp. 780-787, 2001.

[13] D. J. Buysse, C. F. Reynolds III, T. H. Monk, C. C. Hoch, A. L. Yeager, and D. J. Kupfer, "Quantification of subjective sleep quality in healthy elderly men and women using the Pittsburgh Sleep Quality Index (PSQI)," Sleep, vol. 14, no. 4, pp. 331-338, 1991.

[14] M. Á. García-Jiménez, F. Salcedo-Aguilar, F. M. Rodríguez-Almonacid et al., "Prevalencia de los trastornos del sueño en adolescentes de Cuenca, España," Revista de Neurologia, vol. 39, no. 1, pp. 18-24, 2004.

[15] B. Bharti, P. Malhi, and S. Kashyap, "Patterns and problems of sleep in school going children," Indian Pediatrics, vol. 43, no. 1, pp. 35-38, 2006. 
[16] A. BaHammam, E. AlFaris, S. Shaikh, and A. bin Saeed, "Prevalence of sleep problems and habits in a sample of Saudi primary school children," Annals of Saudi Medicine, vol. 26, no. 1, pp. 7-13, 2006.

[17] A. M. Meijer, H. T. Habekothé, and G. L. H. van den Wittenboer, "Time in bed, quality of sleep and school functioning of children," Journal of Sleep Research, vol. 9, no. 2, pp. 145-153, 2000.

[18] E. Lugaresi, F. Cirignotta, M. Zucconi, S. Mondini, P. L. Lenzi, and G. Coccagna, "Good and poor sleepers: an epidemiological survey of the San Marino population," in Sleep/Wake Disorders: Natural History, Epidemiology, and Long-Term Evolution, C. Guilleminault and E. Lugaresi, Eds., pp. 1-12, Raven Press, New York, NY, USA, 1983.

[19] P. Salzarulo, G. Formicola, P. Lombardo et al., "Functional uncertainty, aging and memory processes during sleep," Acta Neurologica Belgica, vol. 97, no. 2, pp. 118-122, 1997.

[20] T. Akerstedt, K. Hume, D. Minors, and J. Waterhouse, "The subjective meaning of good sleep, an intraindividual approach using the Karolinska Sleep Diary," Perceptual and Motor Skills, vol. 79, no. 1, pp. 287-296, 1994.

[21] G. Kecklund, T. Akerstedt, and J. Axelsson, "Day-to-day determinants of sleep quality: a longitudinal diary study," Sleep, vol. 26, p. A300, 2003.

[22] B. W. Ellis, M. W. Johns, R. Lancaster, P. Raptopoulos, N. Angelopoulos, and R. G. Priest, “The St. Mary's Hospital sleep questionnaire: a study of reliability," Sleep, vol. 4, no. 1, pp. 93-97, 1981.

[23] C. H. Bastien, Ã. Fortier-Brochu, I. Rioux, M. LeBlanc, M. Daley, and C. M. Morin, "Cognitive performance and sleep quality in the elderly suffering from chronic insomnia: relationship between objective and subjective measures," Journal of Psychosomatic Research, vol. 54, no. 1, pp. 39-49, 2003.

[24] S. V. Argyropoulos, J. A. Hicks, J. R. Nash et al., "Correlation of subjective and objective sleep measurements at different stages of the treatment of depression," Psychiatry Research, vol. 120, no. 2, pp. 179-190, 2003.

[25] A. G. Harvey, K. Stinson, K. L. Whitaker, D. Moskovitz, and H. Virk, "The subjective meaning of sleep quality: a comparison of individuals with and without insomnia," Sleep, vol. 31, no. 3, pp. 383-393, 2008.

[26] G. Keklund and T. Åkerstedt, "Objective components of individual differences in subjective sleep quality," Journal of Sleep Research, vol. 6, no. 4, pp. 217-220, 1997.

[27] R. E. Dahl, “The impact of inadequate sleep on children's daytime cognitive function," Seminars in Pediatric Neurology, vol. 3, no. 1, pp. 44-50, 1996.

[28] A. M. Meijer, "Chronic sleep reduction, functioning at school and school achievement in preadolescents," Journal of Sleep Research, vol. 17, no. 4, pp. 395-405, 2008.

[29] J. Tynjala, L. Kannas, and R. Valimaa, "How young Europeans sleep," Health Education Research, vol. 8, no. 1, pp. 69-80, 1993.

[30] J. F. Dewald, A. M. Meijer, F. J. Oort, G. A. Kerkhof, and S. M. Bögels, "The influence of sleep quality, sleep duration and sleepiness on school performance in children and adolescents: a meta-analytic review," Sleep Medicine Reviews, vol. 14, no. 3, pp. 179-189, 2010.

[31] H. Caci, P. Robert, C. Dossios, and P. Boyer, "L'échelle de matinalité pour enfants et adolescents: propriétés psychométriques et effet du mois de naissance," Encéphale, vol. 31, no. 1, pp. 5664, 2005.
[32] A. R. Wolfson, M. A. Carskadon, C. Acebo et al., "Evidence for the validity of a sleep habits survey for adolescents," Sleep, vol. 26, no. 2, pp. 213-216, 2003.

[33] A. R. Wolfson and M. A. Carskadon, "Sleep schedules and daytime functioning in adolescents," Child Development, vol. 69, no. 4 , pp. 875-887, 1998.

[34] M. A. Carskadon, R. Feifer, and C. Acebo, "Reliability of six scales in a sleep questionnaire for adolescents," Journal of Sleep Research, vol. 20, p. 421, 1991.

[35] P. M. Russo, O. Bruni, F. Lucidi, R. Ferri, and C. Violani, "Sleep habits and circadian preference in Italian children and adolescents," Journal of Sleep Research, vol. 16, no. 2, pp. 163-169, 2007.

[36] F. Giannotti, F. Cortesi, T. Sebastiani, and C. Vagnoni, "Sleeping habits in Italian children and adolescents," Sleep and Biological Rhythms, vol. 3, no. 1, pp. 15-21, 2005.

[37] F. Giannotti, F. Cortesi, T. Sebastiani, and S. Ottaviano, "Circadian preference, sleep and daytime behaviour in adolescence," Journal of Sleep Research, vol. 11, no. 3, pp. 191-199, 2002.

[38] A. Hvolby, J. Jørgensen, and N. Bilenberg, "Sleep and sleep difficulties in Danish children aged 6-11 years," Ugeskrift for Laeger, vol. 170, no. 6, pp. 448-451, 2008.

[39] L. Tikotzky and A. Sadeh, "Sleep patterns and sleep disruptions in kindergarten children," Journal of Clinical Child and Adolescent Psychology, vol. 30, no. 4, pp. 581-591, 2001.

[40] J. A. Owens, A. Spirito, M. McGuinn, and C. Nobile, "Sleep habits and sleep disturbance in elementary school-aged children," Journal of Developmental and Behavioral Pediatrics, vol. 21, no. 1, pp. 27-36, 2000.

[41] A. Sadeh, "Evaluating night wakings in sleep-disturbed infants: a methodological study of parental reports and actigraphy," Sleep, vol. 19, no. 10, pp. 757-762, 1996.

[42] G. M. Kieckhefer, M. J. Lentz, S. Y. Tsai, and T. M. Ward, "Parent-child agreement in report of nighttime respiratory symptoms and sleep disruptions and quality," Journal of Pediatric Health Care, vol. 23, no. 5, pp. 315-326, 2009.

[43] J. Owens, R. B. Sangal, V. K. Sutton, R. Bakken, A. J. Allen, and D. Kelsey, "Subjective and objective measures of sleep in children with attention-deficit/hyperactivity disorder," Sleep Medicine, vol. 10, no. 4, pp. 446-456, 2009.

[44] J. Mantz, A. Muzet, and R. Neiss, "Le sommeil de l'enfant de 6 ans: enquête en milieu scolaire," Archives de Pediatrie, vol. 2, no. 3, pp. 215-220, 1995.

[45] A. Sadeh, A. Raviv, and R. Gruber, "Sleep patterns and sleep disruptions in school-age children," Developmental Psychology, vol. 36, no. 3, pp. 291-301, 2000.

[46] A. Gaina, M. Sekine, S. Hamanishi, X. Chen, and S. Kagamimori, "Gender and temporal differences in sleep-wake patterns in Japanese schoolchildren," Sleep, vol. 28, no. 3, pp. 337342, 2005.

[47] B. Zhang and Y. K. Wing, "Sex differences in insomnia: a metaanalysis," Sleep, vol. 29, no. 1, pp. 85-93, 2006.

[48] E. O. Bixler, M. N. Papaliaga, A. N. Vgontzas et al., "Women sleep objectively better than men and the sleep of young women is more resilient to external stressors: effects of age and menopause," Journal of Sleep Research, vol. 18, no. 2, pp. 221228, 2009.

[49] A. Ghanizadeh, M. Kianpoor, M. Rezaei et al., "Sleep patterns and habits in high school students in Iran," Annals of General Psychiatry, vol. 7, p. 5, 2008.

[50] M. Wittmann, J. Dinich, M. Merrow, and T. Roenneberg, "Social jetlag: misalignment of biological and social time," Chronobiology International, vol. 23, no. 1-2, pp. 497-509, 2006. 
[51] B. Anderson, A. Storfer-Isser, H. G. Taylor, C. L. Rosen, and S. Redline, "Associations of executive function with sleepiness and sleep duration in adolescents," Pediatrics, vol. 123, no. 4, pp. e701-e707, 2009.

[52] G. Fallone, J. A. Owens, and J. Deane, "Sleepiness in children and adolescents: clinical implications," Sleep Medicine Reviews, vol. 6, no. 4, pp. 287-306, 2002.

[53] J. Taillard, P. Philip, and B. Bioulac, "Morningness/eveningness and the need for sleep," Journal of Sleep Research, vol. 8, no. 4, pp. 291-295, 1999.

[54] C. N. Semler and A. G. Harvey, "Misperception of sleep can adversely affect daytime functioning in insomnia," Behaviour Research and Therapy, vol. 43, no. 7, pp. 843-856, 2005. 


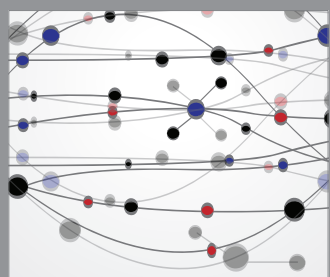

The Scientific World Journal
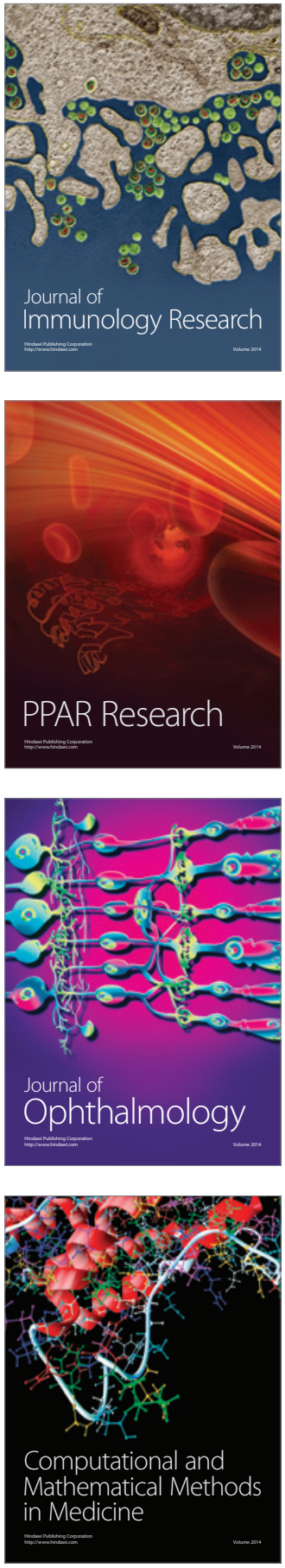

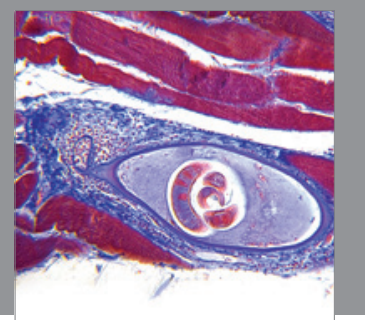

Gastroenterology

Research and Practice
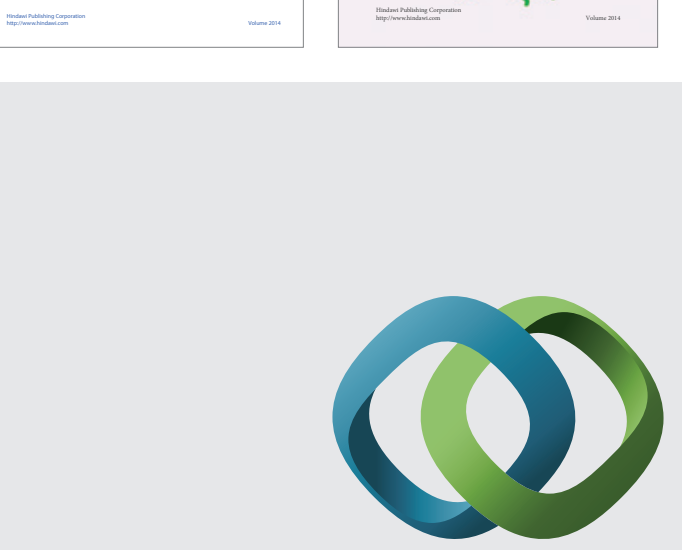

\section{Hindawi}

Submit your manuscripts at

http://www.hindawi.com
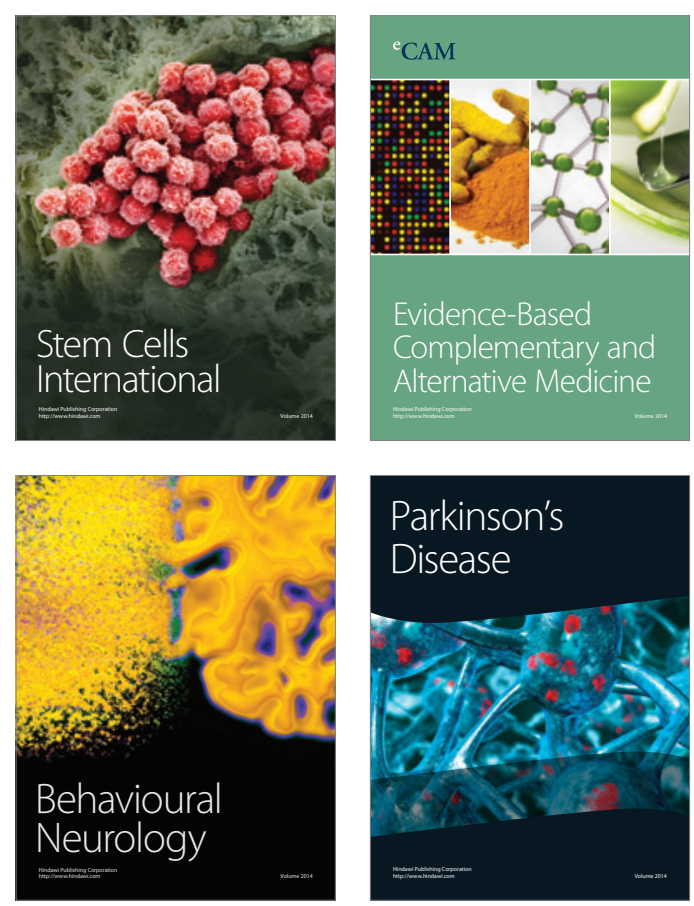

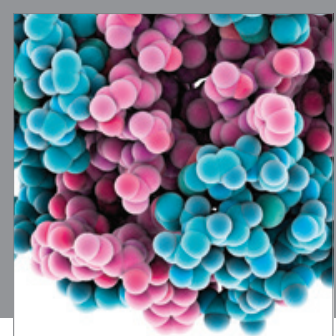

Journal of
Diabetes Research

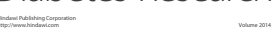

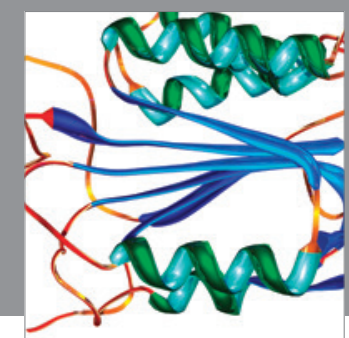

Disease Markers
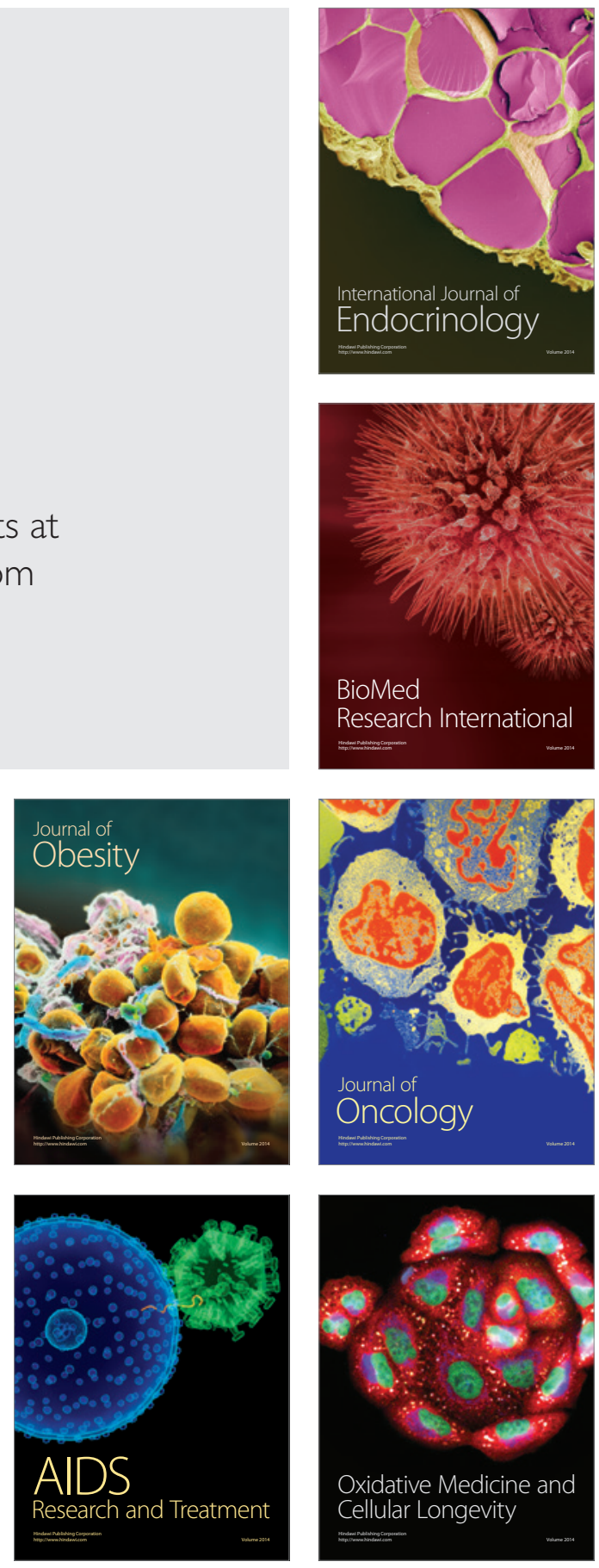